\title{
A CERTIFICAÇÃO FAIR TRADE NA WFTO: UM ESTUDO SOBRE PRINCÍPIOS E CRITÉRIOS PARA SEGURANÇA DO CONSUMIDOR
}

\author{
Joana Stelzer * \\ Keite Wieira **
}

\begin{abstract}
RESUMO
O Fair Trade envida esforços para comercializar produtos de organizações sustentáveis, especialmente localizadas em países em desenvolvimento. A WFTO representa um dos principais atores globais no âmbito do Comércio Justo e congrega associados que defendem seus princípios, conforme critérios de admissão. O objetivo geral da presente investigação busca avaliar esses parâmetros para trazer elementos de discussão relativos à segurança da certificação nas relações de consumo. Com base nessas informações, descreveu-se a certificação do projeto Toca Tapetes. O método utilizado é crítico indutivo e os meios são bibliográficos. De cunho descritivo, os resultados foram expostos por textos.
\end{abstract}

Palavras Chaves: Comércio Justo; Certificação; World Fair Trade Organization (WFTO); Justiça Comercial; Critérios de Conformidade

\section{FAIR TRADE CERTIFICATION AT WFTO: A STUDY ON PRINCIPLES AND CRITERIA FOR CONSUMER SAFETY}

\begin{abstract}
Fair Trade strives to market products from sustainable organizations, especially those located in developing countries. WFTO represents one of the main global actors in the field of Fair Trade and congregates associates who defend their principles, according to admission criteria. The general objective of the present investigation seeks to evaluate these parameters to bring elements of discussion regarding the security of certification in consumer relations. Based on this information, the certification of Toca Tapetes project was described. The method used is critical inductive and bibliographic means. Descriptively, the results were presented by texts.
\end{abstract}

Keywords: Fair Trade; Certification; World Fair Trade Organization (WFTO); Commercial Justice; Compliance Criteria.

\footnotetext{
* Doutora e Mestre em Direito pela Universidade Federal de Santa Catarina (UFSC). Coordenadora do Núcleo de Extensão em Fair Trade/Comércio Justo (NEFT/UFSC). Professora credenciada no Programa de Pós-Graduação em Direito da Universidade Federal de Santa Catarina (PPGD/CCJ/UFSC). Email: joana.stelzer@ufsc.br

${ }^{* *}$ Mestranda em Direito pela Universidade Federal de Santa Catarina (UFSC). Pós-graduada em Direito da Aduana e do Comércio Exterior Brasileiro pela Universidade do Vale do Itajaí (UNIVALI). Advogada. Email: keitewieira@ hotmail.com.
} 


\section{Introdução}

A consecução de uma justiça comercial geral e defensora dos interesses das presentes e futuras gerações é possível, especialmente quando o consumo deixa de ser uma atitude egoísta de satisfação para se transformar em ato político de inclusão social. Contemporaneamente, o cenário do comércio externo reflete uma história herdada da formação do capitalismo. O Fair $T_{\text {Trade }}{ }^{1}$, por sua vez, ainda é um fenômeno de pequenas proporções econômicas, embora em franco crescimento. No entanto, é reconhecido pela sociedade transnacional que vê em seus princípios a sustentabilidade ambiental, social e econômica, requisitada nos círculos acadêmicos e na sociedade civil, nos mais variados estudos.

Este artigo tem como ponto de partida a compreensão do processo de certificação perante a World Fair Trade Organization (WFTO). Em 1987, 11 importadores europeus constituíram a Associação Europeia de Comercio Justo, e dois anos mais tarde, em 1989, criouse a International Fair Trade Association (IFAT). Durante a Assembleia Geral Anual de 2009, em Katmandu, em substituição à IFAT surgiu a WFTO. A WFTO representa um dos principais atores globais no âmbito do Comércio Justo. O Fair Trade envida esforços para comercializar produtos de organizações sustentáveis, especialmente localizadas em países em desenvolvimento, para alterar injustas estruturas do comércio mundial. Na outra ponta do processo estão os consumidores, sujeitos que impulsionam a relação negocial à medida que podem se transformar em agentes de transformação.

Do exposto, a problematização consiste no seguinte: quais são os princípios e as principais etapas que devem ser seguidas para alcançar o processo de certificação perante a WFTO no intuito de fazer parte dessa Organização de Fair Trade? Para tal hipótese, apresentaram-se os critérios de conformidade extraídos do WFTO Guarantee System Handbook e que devem ser necessariamente alcançados para a admissão e permanência do membro junto ao organismo. Nesse sentido, analisar-se-á como ocorre a implementação de tais critérios e um breve relato sobre um estudo de caso. O estudo levou em consideração os critérios para

\footnotetext{
${ }^{1}$ As expressões Fair Trade e Comércio Justo não retratam mera tradução entre si, mas, sinalizam divergências ideológicas. Enquanto a lógica do Fair Trade possui caráter mais assistencialista visando à diminuição da pobreza, o movimento Comércio Justo parte de entendimento diferente, pois a pobreza nada mais é que consequência das injustas estruturas comerciais. Embora essa temática seja de grande riqueza, na presente investigação o objetivo se concentrou no processo de certificação Fair Trade. Quanto à concepção de fazer do comércio uma ferramenta de sustentabilidade e o consumo uma ação política, ambos movimentos convergem.
} 
certificação de membro provisório e obrigatório (com data prevista para serem alcançados), além dos parâmetros de melhoria contínua estabelecidos pelo controle de qualidade da WFTO que, quando preenchidos, elevam o membro à qualidade de definitivo.

Tendo em vista tais apontamentos, o objetivo geral da presente investigação consiste em evidenciar os critérios Fair Trade para certificação e a possível habilitação entre seus membros. Os objetivos específicos que permitiram o alcance do objetivo geral foram: descrever o funcionamento do Fair Trade enquanto fenômeno; discutir a certificação nas relações de consumo; apontar as etapas que devem ser percorridas para consecução da certificação. Modo geral, buscou-se induzir a reflexão acerca da certificação e da validade de seu uso.

Entre as teorias que se apresentam para explicar essa inédita realidade enveredou-se pela contribuição Laura Raynolds, especialmente The challenges of transforming globalization, além de destacados autores, como Stelzer e Gonçalves, e Elias Fajardo. Uma vez estabelecido o marco teórico, a análise voltou-se para os princípios do Comércio Justo e para a discussão acerca da sua implementação e a garantia por intermédio da certificação. Ao final, descreveuse a certificação da Associação Toca Tapetes para ilustrar destacadas etapas desse processo. Nesse sentido, auxiliou a investigação de Luis Moretto Neto e Valentina Gomes Haensel Schmitt, além da documentação da WFTO.

O método utilizado foi o crítico indutivo, avaliando-se os dados e as informações sob forma qualitativa. Os meios utilizados foram bibliográficos, com usos de reconhecidos sites institucionais. A coleta foi realizada por duas fontes secundárias de informação: relatórios institucionais e produção científica de reconhecidas obras doutrinárias. Quanto aos fins, a pesquisa apresenta-se de cunho descritivo e os resultados foram expostos exclusivamente em forma de textos.

\section{Movimento Social de Fair Trade}

O Fair Trade é um movimento social que se fundamenta na solidariedade econômica. Sobre tal propósito, propõe uma parceria comercial entre os produtores e consumidores procurando minimizar as desigualdades no comércio por meio da proximidade e respeito à condição social dos produtores, seguindo normas justas.

Revista de Direito, Globalização e Responsabilidade nas Relações de Consumo | e-ISSN: 2526-0030 | Maranhão | v. 3 | n. 2 | p. 
O Comércio Justo se baseia na solidariedade econômica e financeira. Nas transações comerciais não existem vencidos nem vencedores, pois se procura evitar que uma parte perca para que a outra possa ganhar. Quanto todas as partes envolvidas ganham, a atividade comercial adquire um caráter mais igualitário e estimulante. [...] $\mathrm{O}$ Comércio Justo não se restringe às relações comerciais; inclui também iniciativas de cooperação entre produtores, importadores, e consumidores, que podem inclusive se desdobrar em atividades paralelas ligadas à gestão, ao treinamento de pessoal especializado e ao associativismo. (FAJARDO, 2010. p. 54)

O Fair Trade está ligado à ideia de progresso social, bem como as iniciativas de cooperativismo, uma vez que busca, por comércio alternativo, combater um sistema global de trocas em mundo repleto de grandes corporações e oportunidades desiguais. O movimento, mais do que trazer oportunidades aos produtores em desvantagem, visa ao desenvolvimento das comunidades nas quais os produtores (ou artesão) estão inseridos.

Há quem remeta o surgimento do Fair Trade aos anos posteriores ao Segundo Grande Conflito, quando as igrejas promoviam artesanatos oriundos de famílias europeias atingidas pela guerra, criando a delimitação basilar dos princípios de justiça social e equidade do movimento para estancar as injustiças enfrentadas em um comércio desigual (MURRAY; RAYNOLDS, 2007, p. 7). Ademais, no período pós-guerra mundial verificou-se o aumento da produção agro-industrial que passou à proliferação de produtos dessa natureza, intensificando o uso de química e tecnologia na produção (MURRAY; RAYNOLDS, 2007, p. 34), fenômeno que aumentou a produção, mas, promoveu a necessidade de um contra movimento. A partir da década de 1960, o Fair Trade iniciou sua consolidação na Europa.

O Comércio Justo, inicialmente, chamado de comércio alternativo, teve sua origem
na Europa em 1967, quando pequenos grupos de pessoas comprometidas com causas
sociais tiveram a intenção de apoiar os pequenos produtores dos países do Sul, com
um pagamento que correspondia ao trabalho investido na produção e transformação
de seus produtores. Pretendia-se criar um sistema alternativo a partir de relações
diretas e de longo prazo entre os grupos organizados de pequenos produtores e de
compradores e importadores para diminuir ou eliminar o sistema convencional e que
atuava, ao contrário de maioria dos intermediários, conhecidos no México como
coiotes, quem busca pagar aos produtores os preços mais baixos possíveis para obter
os maiores ganhos. (FLORES, 2006. p. 83)

Na América Latina, o Comércio Justo tomou destaque no final da década dos anos 80, com o selo Max Havelaar do café cultivado por índios mexicanos, circunstância que exerceu forte influência nos países latinos. Posteriormente, sob tal enredo desenvolver-se-iam outras propostas. Nesse sentido, surgiu a Coordinadora Latinoamericana y del Caribe de Pequeños 
Productores de Comercio Justo (CLAC), mais importante organismo na promoção do Comércio Justo em todo o continente latino-americano e que "tem suas raízes na criação dos primeiros selos de Comércio Justo, no final dos anos 80." (CLAC, 2016)" Progressivamente, o Comércio Justo cresceu na América Latina. Comércio Justo latino-americano e o Fair Trade são convergentes, embora guardem ideologias distintas entre si.

[...] é interessante notar que o Comércio Justo e Solidário está ganhando terreno [...] em toda a América Latina, destacando-se a criação e o fortalecimento de diferentes redes de articulação, como a Associação Latino-Americana de Comercio Justo (WFTO-LA), a Rede Latino-Americana de Comercialização Comunitária (RELACC) e a Coordenadora Latino-Americana e Caribe de Pequenos Produtores de Comercio Justo (CLAC), que promovem diálogo, fazem incidência política e articulam convergências e ações conjuntas na região. (GOMES, 2017, p.62)

As dificuldades de afirmação do Fair Trade perante o comércio convencional são reconhecidamente complexas.

\begin{abstract}
Primeiramente, [o Fair Trade] fornece aos produtores preços que são maiores do que os convencionais no mercado internacional, particularmente em mercados voláteis de mercadorias tropicais. Em segundo, apoia a construção de capacitação organizacional dos grupos democráticos que representam os produtores em pequenas escalas (por meio de cooperativas) e trabalhadores (pela união). Em terceiro, aumenta a produção e habilidades de marketing para os participantes e suas famílias que se estendem à produção do Fair Trade. Em quarto, fornece um prêmio para financiar projetos mais amplos das comunidades tais como clínicas de saúde, escolas, melhores rodovias e sistema sanitário e outros serviços sociais. (MURRAY; RAYNOLDS, 2007, p.05)
\end{abstract}

Para Murray e Raynolds (2007, p. 4), o Fair Trade é uma resposta aos efeitos negativos da globalização, uma vez que busca criar um futuro socialmente e sustentavelmente mais justo. Sob tal ótica, guia-se por objetivos, dentre os quais:

1 Melhorar a vida e bem-estar dos produtores por meio de um melhor acesso ao mercado, fortalecendo as organizações produtoras, pagando um melhor preço e promovendo a continuidade na relação de comércio; 2 Promover oportunidades de desenvolvimento para produtores em desvantagem, principalmente mulheres e indígenas, além de proteger crianças de exploração no processo de produção; 3 Alertar os consumidores sobre os efeitos negativos que afligem produtores do comércio internacional, para que eles possam exercitar o seu poder de compra de forma positiva; 4 Dar exemplo de parceria no comércio por meio de diálogo, transparência e respeito; 5 Lutar por mudanças nas regras e práticas do comércio internacional convencional; 6 Proteger os direitos humanos por meio de justiça social, práticas saudáveis ao meio ambiente e segurança social. (MURRAY; RAYNOLDS, 2007, p. 5). 
Dessa maneira, sustenta-se que as principais características do Fair Trade e que correspondem aos seus standards, podem ser resumidas no seguinte: no cooperativismo e associativismo, em preços justos, na ligação entre produtor e consumidor; nas relações duradouras; na rejeição de discriminação de raça, gênero e religião nas relações comerciais; na rejeição do trabalho infantil, do trabalho escravo; na preservação da saúde; na conservação dos recursos naturais; no respeito aos direitos trabalhistas; nas relações éticas; no financiamento da produção ou do plantio; no respeito à legislação e às normas nacionais e internacionais referente à qualidade do produto e garantia de um ambiente de trabalho seguro (FAJARDO, 2010, p. 61$62)$.

Em tal contexto, surgiu a WFTO, uma organização global de comerciantes justos que, por intermédio de um Sistema de Garantia pautado por 10 princípios - produtores, exportadores, importadores, varejistas, consumidores, entre outros - une-se em prol de melhores práticas de comércio. A WFTO tem mais de 370 organizações e 40 sócios individuais (como membros), oriundos de 70 países, distribuídos nos cinco continentes. Como uma rede global, a WFTO possui escritórios regionais nos cinco continentes (WFTO, 2017). A WFTO corrobora com os princípios supramencionados. Segundo esses princípios, o movimento busca realinhar o desenvolvimento de localidades com reflexos em âmbito internacional.

Dentre a proposta, verifica-se que esse tipo de comércio marcou o crescimento das localidades isoladas, bem como possibilitou o relacionamento entre povos de diferentes regiões e culturas. Por intermédio de um movimento sustentável, almeja-se um inédito alinhamento e novas perspectivas comerciais em prol da melhoria da qualidade de vida das comunidades locais, além do respeito e dignidade da pessoa humana, no contexto de regras justas (nesse caso do comércio internacional, mas também poderia ser do comércio local).

Sob tal signo, inclui-se a proibição do trabalho infantil e a promoção da educação, associando a educação ao desenvolvimento social. De igual modo, ao repudiar o trabalho escravo, insere-se a conscientização do valor à vida e ao trabalho como possível fonte de realização pessoal; ao rejeitar a discriminação de raça, gênero e religião nas relações comerciais emerge a ideia de igualdade e de liberdade de condições; ao valorizar ambiente de trabalho seguro, mais do que evitar acidentes, preza-se pela saúde do produtor e por qualidade de vida.

Do ponto de vista ambiental, defende-se a conservação dos recursos naturais como pressuposto de continuidade do serviço comercial com excelência. Nesse sentido, também se relaciona o movimento de Fair Trade com a nova definição de qualidade que é dada aos 
produtos provenientes da agricultura. Afinal, o denominado agrobusiness tem trazido uma série de dificuldades ao equilíbrio ambiental, além do uso excessivo de agrotóxicos e a contaminação dos próprios alimentos no afã de alcançar alta produtividade. Nessa senda, o próprio conceito de qualidade teve que tomar novos rumos em prol da justiça social. Conforme expõem Murray e Raynolds (2007, p. 37), o conceito de qualidade tem se redefinido em torno de um sentido social. Mais do que características dos produtos como tamanho ou cor, as questões sociais inerentes à produção têm sido analisadas para o fim de redefinir o conceito de qualidade.

Observando-se os princípios do Fair Trade, pode-se afirmar que a justiça social almejada pelo movimento tem muito a acrescentar no conceito de qualidade. Diante da ausência de mecanismos normativos para que se trave, de forma efetiva, a luta contra as atrocidades sociais no comércio - principalmente em esfera internacional - a ferramenta que se tem é a conscientização dos consumidores sobre o que de fato representa um produto com qualidade. Para essa difícil tarefa, ampliar o conceito de qualidade, infiltrando em suas bases as questões sociais, parece ser o caminho mais adequado.

Ao conscientizar o consumidor, cria-se um impacto na vida dos produtores por trás do cultivo, sendo possível desestimular as políticas antissociais e dar força àqueles que estabelecem princípios justos em sua produção (e que pode ser estendido ao transporte e à distribuição, além da própria comercialização). Entende-se que o Fair Trade seja capaz de promover essa conscientização e esse novo rumo em busca da qualidade social, já que seus fundamentos de valorização do produtor, pagamento de preço justo, combate a trabalho escravo, por exemplo, são eficazes na implementação dessa qualidade almejada.

\footnotetext{
O sucesso do Fair Trade tem sido notável. Em menos de duas décadas, ele cresceu de um nicho obscuro de mercado para um fenômeno globalmente conhecido. O Fair Trade evoluiu de um movimento de igreja pequena e de apelo solidário de país de terceiro mundo para uma minoria de consumidores motivados conscientemente, para um movimento com acesso convencional ao mercado expandido, direcionado À massa convencional de consumidores (MURRAY; RAYNOLDS, 2007, p. 5).
}

Há distintas formas de conectar o consumidor ao Fair Trade, que pode ir desde a venda direta entre produtor e consumidor até a utilização de interposta pessoa. Nesse último caso, o selo de certificação será a identidade visual, especialmente nas grandes redes varejistas. O selo que busca comprovar a procedência de um bem tem progressivamente se revelado o elo mágico 
que viabiliza o consumo sustentável. No entanto, a 'garantia' também tem sido objeto de farsa, fragilizando o processo.

De acordo com a Instituto Brasileiro de Análises Sociais e Econômicas (IBASE, 2017), a concepção de certificar produtos possui origem histórica na França, no início do século 20, ocasião na qual quando pequenos produtores de vinho passaram a diferenciar sua bebida daquela produzida em larga escala por processos industriais. Sob tal lógica, emergiram outras propostas, passando - principalmente - a ser uma exigência do mercado. Essa situação fez que o fabricante de macarrão, por exemplo, quisesse certificar que sua massa era feita de ovos (e não de corantes), entre outras múltiplas situações. Na esteira dessa tendência, houve proliferação de selos nas embalagens. (IBASE, 2017)

No mais, a certificação é o meio pelo qual o produtor informa que está comprometido com um movimento socialmente responsável e também preocupado com o meio ambiente, proporcionando um produto diferenciado ao consumidor (GRODNIK; CONROY, 2007, p. 100). A certificação deve assegurar a confiança no processo, mas, as diferentes propostas de sustentabilidade e a ausência de fiscalização fizeram com que muitos selos caíssem em descrédito.

\footnotetext{
Os selos de certificação representam tentativas de garantir que o consumidor tenha informações sobre a procedência dos produtos. [...] De maneira geral, a certificação permite monitorar as condições de produção e comercialização dos itens oferecidos no mercado. Um produto certificado dá segurança ao consumidor. E, para o produtor, facilita o acesso aos pontos de venda. (FAJARDO, 2010, p. 40; 65).
}

Em que pese a polêmica acerca do assunto, já que a doutrina não é unânime quanto à validade desse recurso, passa-se a explorar a certificação WFTO referente à membresia, no intuito de descrever os procedimentos desse organismo e, ao final, retratar um breve estudo de caso denominado Associação Toca Tapetes.

\section{A WFTO e a Certificação Fair Trade}

A World Fair Trade Organization (WFTO) "[...] é um networking global de organizações que representam a cadeia logística do Fair Trade. A membresia da WFTO fornece credibilidade e identidade à organização por meio de um sistema de garantia internacional [...]” (WFTO, 2017). Em outras palavras, a WFTO é uma organização que reúne membros 
certificados e que remete à conformidade com o Fair Trade. Para tanto, estipula critérios com princípios de sustentabilidade para a admissibilidade e permanência na organização.

Com intuito de aprofundar o modo de operacionalização, parte-se para a análise dos procedimentos adorados pela WFTO que, ao certificar o membro, recebe o requerente no sistema. O principal compromisso da WFTO é a luta contra a pobreza, desigualdade de comércio, mudanças climáticas e crises econômicas. A organização acredita ser o Fair Trade a solução global para problemas dessa espécie. (WFTO, 2017) Visando ao benefício dos mais vulneráveis produtores das cadeias mundiais de comércio, a organização busca proporcionar um estilo de vida sustentável. Para alcançar seu objetivo e cumprir com seus preceitos, a WFTO funciona como rede global.

Seguindo a estrutura simplificada de uma associação, todos os membros (organizações ou indivíduos certificados) são convidados para se reunirem na Reunião Anual Geral (Annual General Meeting - AGM) quando se forma o maior corpo deliberativo da organização, responsável, inclusive, pela eleição do presidente e dos cinco diretores, cada um destinado a representar a WFTO nas cinco agências distribuídas pelo globo. (WFTO, 2017)

As cinco regiões atendidas pela organização certificadora são WFTO África, WFTO Ásia, WFTO Europa, WFTO América Latina e WFTO Pacífico (incluindo a América do Norte e a Oceania). (WFTO, 2017) Distribuídas com o propósito de propagar os princípios do Comércio Justo pelo mundo, as sucursais da WFTO seguem o mesmo regimento e política.

As certificadoras surgiram no final da década de 1980 e desenvolveram critérios específicos para cada produto a ser certificado (FAJARDO, 2010, p. 65). Utilizando-se da essência dos standards do Fair Trade a partir da iniciativa Max Havellar (Holanda), de 1987, expandiram-se posteriormente (BARRIENTOS; JONES, 2007, p.54). Desde sua criação, o procedimento da certificação objetivou a veiculação dos produtos certificados para as lojas e supermercados, colocando-os lado a lado com produtos comuns (BARRIENTOS; CONROY; JONES, 2007, p. 54) e proporcionando ao consumidor o poder de escolher um produto com selo Fair Trade.

Essa promoção pode ser considerada eficaz, especialmente por decorrência de uma pesquisa, na qual se constatou que em cada dois adultos do Reino Unido, ao menos um indivíduo reconhece o selo da FLO (Fair Trade Labelling Organization), Organização de 
Certificação de Fair Trade International (BARRIENTOS; SMITH, 2007, p.106), especialmente relacionada aos produtos.

A certificação WFTO decorre de requisitos previamente determinados, tendo sido desenvolvidos a partir de experts da área que, além de criarem os parâmetros, também monitoram e verificam a conformidade do modo operacional dos integrantes. (WFTO, 2017) Além dos experts treinados pela própria organização, os demais membros de uma determinada região também são responsáveis pela implementação e adequação dos princípios do Fair Trade, inclusive para declarar um requisitante apto a se tornar membro provisório.

Tendo feito tais considerações, seguem os princípios já mencionados acima como fundamentais ao movimento e, consequentemente, pilares da organização certificadora em questão. Junto de cada princípio, analisar-se-ão as atividades necessárias e condições mínimas que devem ser atingidas pelas organizações e associações, ou até indivíduos, que pretendam se tornar membros da WFTO.

Para facilitar a compreensão dos objetivos abaixo relacionados, cumpre ressaltar que por ocasião do pedido de membresia são analisados requisitos mínimos para a adequação ao movimento e, com a aceitação, o requerente torna-se membro provisório. Após a aprovação dessa membresia (provisória), ocorre a auditoria dos experts da WFTO que irão determinar quais objetivos devem ser alcançados em tempo determinado e quais preceitos e práticas devem ser motivo de melhoria contínua.

Relativamente às atividades a serem desenvolvidas e aos objetivos a serem alcançados, dividem-se em: obrigatórias para tornar-se membro provisório (mandatory), obrigatórias em até $x$ anos (mandatory by year $x$ ) e de melhoria contínua (continuous improvment). Feitas tais colocações, passa-se a análise da implementação dos princípios essenciais para a certificação, bem como de seus critérios de conformidade (mandatory, mandatory by year $x$ e continuous improvment).

\section{Os princípios WFTO e seus critérios de conformidade}

Todos os princípios e critérios de conformidades abaixo relacionados foram retirados do WFTO Guarantee System Handbook disponível no site da organização. Deixa-se de citar alguns critérios de conformidade, tendo sido escolhidos aqueles essenciais ao desenvolvimento do presente estudo, selecionados por critério de adequação. Considerando que, ao final, será 
feito um estudo de caso, será em relação ao ramo de atividades da Associação Toca Tapetes que serão avaliados os standards.

\subsection{Concepção dos princípios Fair Trade}

Avaliando-se o direito do comércio internacional e sua manipulação pelos detentores do poder, posteriormente legitimado em regras de direito internacional, não é difícil de entender acerca da necessidade de princípios que promovam a sustentabilidade em múltiplas dimensões, sejam elas ambientais, humanas, culturais, entre outras. Assim, passa-se a avaliar os dez princípios abaixo, no intuito de perceber os valores humanistas universais que os caracterizam, enquanto mote de direito transnacional que orienta o Fair Trade. Sob a vertente da transnacionalidade, os princípios são respeitados por produtores, comerciantes e consumidores. Trata-se de um corpo normativo cogente, enquanto máximas universais, aceitas e defendidas pelo grupo, independente do Estado ou de instrumentos formais de direito internacional público. São também atitudes aplaudidas pelos consumidores de Fair Trade na aquisição dos seus produtos. Nesse sentido, passa-se a explorar o potencial desses princípios.

$1^{0}$ Princípio: Criação de oportunidades para os produtores em desvantagem econômica - em virtude dos pretendentes a membros serem associações de pequeno porte, a responsabilidade de promoção de oportunidades aos produtores em desvantagem econômica é um aspecto essencial a ser privilegiado pela WFTO. Como critério de melhoria contínua, a organização deve demonstrar o seu compromisso, por meio de suas ações, em promover a melhoria das atividades de comércio e condições sociais e econômicas dos grupos de produtores em desvantagem.

$2^{\circ}$ Princípio: Transparência e prestação de contas - para que se estabeleça o Fair Trade, exige-se, como critério mínimo, a transparência e a prestação de contas na gerência das relações comerciais de cada organização. (WFTO, 2017) Um dos critérios de conformidade obrigatória nesse princípio é ter a descrição completa da estrutura organizacional e do sistema financeiro da administração. Em até quatro anos, é obrigatório que exista uma auditoria externa (há exceções, quando os relatórios e contas podem ser aprovados por outros membros) promovendo a análise das contas da organização. A título de melhoria contínua faz-se 
necessário que o requerente tenha um bom processo de comunicação interna, tais como reuniões e informativos ou cartilhas.

$3^{\circ}$ Princípio: Práticas de Fair Trade - o comércio precisa ser praticado com base na preocupação econômica, ambiental e visando ao bem-estar dos pequenos produtores, não gerando lucro à custa da marginalização do ser humano. É necessário que se tenha compromissos de comércio, respeitando os contratos efetuados, prazos e qualidade, evitando cancelamentos. O pré-financiamento da produção é um indicador importante, devendo o interessado pela compra de artesanato do membro da WFTO, pagar 50\% do valor quando da realização do pedido. Outrossim, a busca por parcerias comerciais para longa data, a competição justa entre concorrentes e a identidade cultural por meio do respeito das habilidades tradicionais dos associados são essenciais.

Como conformidade obrigatória das denominadas Práticas de Fair Trade, faz-se necessário que os associados sejam pagos imediatamente após a entrega dos produtos. É obrigatório em até 2 anos que a organização tenha um sistema transparente para lidar com problemas na qualidade. Para dar continuidade à melhoria, faz-se necessário que se demonstrem esforços em prol do aumento do valor ou da diversidade dos produtos.

$4^{\mathbf{o}}$ Princípio: Pagamento de um preço justo - representa o encontro entre o preço de mercado e o valor que possa proporcionar uma vida digna aos produtores. É obrigatório compreender o custo da produção e o custo de vida daquela localidade, reforçando a ideia de que o lucro de uma parte não pode ser a exploração da outra (seja essa externalidade negativa uma pessoa humana ou a natureza). Em até 2 anos, é obrigatório promover a integração dos produtores na discussão de preço. Em até 4 anos, faz-se imprescindível repassar informações transparentes sobre a cadeia de comércio. Continuamente, a melhoria deve objetivar a estrutura de produção que otimize os benefícios em prol dos produtores.

$5^{\circ}$ Princípio: Erradicação do trabalho infantil e do trabalho forçado/escravo - a WFTO adere à Convenção de Direitos das Crianças da ONU, garantindo aos menores das famílias envolvidas na produção dos bens, seus direitos fundamentais, bem como se certifica que não exista qualquer trabalho forçado ou escravo junto aos associados. (WFTO, 2016) Nesse sentido, há obrigação de existir um sistema de controle das idades de todos os envolvidos na produção. Em até 2 anos é inevitável assegurar que todos os trabalhadores jovens (idade mínima para o início do labor - 17 anos) tenham suas condições laborais estabelecidas conforme a legislação 
local, como por exemplo, a ausência de contato com agentes insalubres. Em até 4 anos, é necessário garantir que não haja, em toda a cadeia de produtores, envolvimento de crianças.

$6^{0}$ Princípio: Não discriminação, igualdade de gênero e liberdade de associação - não poderão estar presentes nenhum tipo de discriminação, seja na contratação, no treinamento, nas promoções ou na aposentadoria por motivos de raça, nacionalidade, religião, idade, obtenção de Human immunodeficiency virus (HIV), entre outros. É assegurado igualdade entre mulheres e homens, respeitando as necessidades de cada um, incluindo a igualdade de salário. É obrigatório que não haja discriminação nos termos acima expostos. Em até 2 anos, é imperativo que se garanta às mulheres salário igual ao dos homens. Referente à melhoria contínua, é necessário proporcionar a mulher condições flexíveis de trabalho para que seja possível conciliar os afazeres familiares, domésticos e laborais.

$7^{\circ}$ Princípio: Garantia de boas condições laborais - é necessário prever segurança, condições saudáveis e horas adequadas de trabalho para todos. Nesse sentido, como critério de conformidade, é fundamental respeitar a legislação relativa às mulheres grávidas e àquelas em período de amamentação. Em até dois anos, é necessário tomar todas as providências corretas quanto aos acidentes e problemas de saúde, evitando casos futuros. Em até 4 anos, precisa-se realizar diversas ações para prevenir riscos de acidentes graves. Continuamente, buscando a melhoria, deverá ser disponibilizada seguridade social acima do mínimo requisitado pelo país.

$8^{\circ}$ Princípio: Promoção de construção de capacidade - visa ao desenvolvimento dos produtores, capacitando-os continuamente. (WFTO, 2016) Em até 2 anos precisa ser desenvolvido um plano e um orçamento para tal capacitação. Em 4 anos, o referido plano deverá estar em prática. Continuamente, os treinamentos devem promover aperfeiçoamentos profissionais, qualidade e design dos produtos, capacidades administrativas e de marketing e implemento dos princípios de Fair Trade.

9 Princípio: Promoção do Fair Trade - os associados são obrigados a promover discussões sobre Fair Trade com os empregados e produtores. Em até 2 anos precisa-se estabelecer a promoção do Fair Trade na comunidade. Continuamente, busca-se o networking entre os parceiros de Fair Trade locais e nacionais.

10 ${ }^{\circ}$ Princípio: Sustentabilidade do Meio Ambiente - faz-se necessário promover a sustentabilidade das técnicas utilizadas na produção, além de otimizar os desperdícios e 
procurar formas de embalagem e meio de entrega saudáveis ao meio ambiente. Como critério de conformidade obrigatório, tem-se como essencial a obediência às normais ambientais locais e nacionais. A título de melhoramento contínuo, precisa-se utilizar produtos reciclados ou materiais facilmente biodegradáveis para embalar os bens produzidos e promover a entrega pela via marítima (menos poluente), sempre que possível.

Tendo analisado os dez princípios e alguns dos critérios de conformidade obrigatórios, com data designada para se tornarem obrigatórios e de contínuo melhoramento, faz-se imperioso retomar a discussão acerca da implementação desses critérios.

\subsection{A implementação dos critérios de conformidade para alcançar a certificação}

Como já se mencionou, é de extrema importância os experts da área dos demais membros locais, além do próprio produtor para a promoção do fenômeno em rede e para a adequada tomada de decisões no que tange à conformidade. Esse processo decisório, ademais, caracteriza-se por englobar os esforços e contribuições de todos os envolvidos e interessados no movimento (BESSON, 2006, p.42) e que, em nível global, dão início à criação e ao estabelecimento das normas e parâmetros do Fair Trade.

Nesse quesito, alguns estudiosos referem-se à produção normativa enquanto direito transnacional, pois deixa de existir a dualidade centro-periferia, passando a qualificar-se como relações transfronteiriças, nas quais há criação de espaços sociais e surgimento de novos sujeitos que operam para dar sustentação à emergente realidade. Surge evidente que uma série de requisitos estruturais do direito internacional clássico não podem ser satisfeitos no emergente contexto. No entanto, verifica-se a importância desses atores na criação de valores e de consenso sobre as normas produzidas. "Na verdade, eles criam uma atmosfera de 'valores globalizados' em face da qual os Estados não podem recuar" (BARROS-PLATIAU, 2014). "O Fair Trade, apesar da turbulência da inevitável certificação, faz crer sobre a possibilidade de alcançar justiça nas relações de troca e a transformação da exploração em solidariedade mundial”. (STELZER; GONÇALVES, 2016)

Com isso, há grande atenção não somente com as condições de trabalho do produtor (além da sua família e comunidade, e que deve se estender por toda a cadeia logística), mas, também com o consumidor que pode adquirir bens de forma ética. Trata-se de um raciocínio muito diferente do praticado pelo neoliberalismo, pois no Comércio Justo as pessoas são consideradas mais importantes que o lucro [...] O Comércio Justo 
foi a necessária resposta ao fracasso do comércio convencional para fornecer meios de subsistência sustentáveis e oportunidades de desenvolvimento para as pessoas em diversos países marginalizados (STELZER; GONÇALVES, 2014).

Já que a essência do movimento é proporcionar a sustentabilidade social aos produtores, são esses agentes que devem ter voz na criação e implementação de standards do Fair Trade, até porque, para ser membro, os ora certificadores devem compreender todas as etapas de adequação. No modo de entender de Andrés Larrinaga Arechaga (2006, p.76), o princípio da participação, que define o envolvimento das associações já membros do sistema certificador, é o que se distingue de qualquer estratégia capitalista.

Para finalizar, queremos manifestar nossa profunda convicção de que toda a iniciativa que pode ser considerada parte de uma estratégia alternativa e popular deve praticar o maior grau possível no princípio da participação. Entendemos que esta é a principal característica que, verdadeiramente, distingue-se de qualquer estratégia capitalista, que é como, desde a Espanica [uma organização de Comércio Justo], se entende o Fair Trade. (ARECHAGA, 2006, p.76)

A criação e implementação de padrões com foco na realidade dos produtores e com a participação dos envolvidos tanto faz parte dos parâmetros da certificação que, quando a certificadora caminha para diferentes localidades do mundo, precisa se reinventar e (re) imaginar a justiça, encontrando respostas para novos questionamentos (KRUGER; TOIT, 2007, p. 200). Partindo-se desse pressuposto, tem-se que as normas para criação, implementação e fiscalização dos critérios de conformidade do Fair Trade (e, logo, da sua certificação), são intercâmbios de ideias, costumes e comportamentos (FAJARDO, 2006, p. 54) ao redor do mundo, concluindo-se, assim, pela forte componente transfronteiriça do processo.

\subsection{A membresia da Associação Toca Tapetes na WFTO: relato de estudo de caso}

A Associação Toca Tapete tem sede no município de Araranguá, no Estado de Santa Catarina. A organização originou-se a partir de artesãs dessa localidade, em um curso de tapeçaria, a partir do qual se articulou a produção sustentável de tapetes, caracterizando-se o artesanato têxtil da região. O fornecedor de matéria-prima e que viria a ser o 'atravessador' da produção pronta trouxe um dilema para os sujeitos, pois o pagamento era irrisório. A decisão das associadas foi migrar do modelo de competição para o de cooperação, por intermédio do 
associativismo (MORETTO; SCHMITT, 2017). Em 2002, passados três anos de reuniões e mantidas as produções individualizadas, nove integrantes optaram pela criação da associação comercial, formada por mulheres (mais de 30 artesãs que já trabalhavam em conjunto, a partir da tradição familiar do tear). No ano de 2004, as produtoras criaram a loja nas margens da BR 101, onde todos os produtos passaram a ser expostos, comercializados e distribuídos (MORETTO; SCHMITT, 2017).

No ano de 2003, as artesãs passaram a ter o acompanhamento de consultoria especializada em gestão e tecelagem - fornecida pelo Serviço Brasileiro de Apoio às Micro e Pequenas Empresas (SEBRAE), dentro do marco de um Projeto da WFTO. ${ }^{2}$ A função do SEBRAE, sob tal ótica, residia enquanto consultor de gestão para pessoas sem o conhecimento técnico profundo no que se referia tanto às funções da administração que deveriam ser observadas, quanto em relação ao Fair Trade, eis que se vislumbrava a necessária adequação das condições exigidas para a certificação da WFTO América-Latina. Ainda hoje uma novidade no Brasil, iniciava-se uma parceria para a certificação. Afinal, partindo-se da ideia de que as barreiras geográficas ou normativas para a implementação dos critérios de conformidade do Fair Trade e da sua certificação eram sutis, o SEBRAE surgia como consultor hábil para auxiliar na adequação.

O principal objetivo da consultoria SEBRAE foi a conscientização do conceito e dos princípios do Fair Trade, por intermédio de palestras e cursos, uma vez que a capacitação e o fornecimento de informações eram meios de inclusão dos pequenos empreendedores (SEBRAE, 2017). A conscientização além de configurar o ponto de partida do projeto delimitado também incluiu a participação das líderes (já que predominam mulheres na associação) em congressos nacionais de Fair Trade. Nesse sentido, as líderes também presenciaram uma feira internacional de artesanato de Fair Trade, além de terem gerido a sua feira na comunidade local.

A consultoria auxiliou as artesãs a preencherem os critérios de conformidade obrigatórios para tornar a associação um membro provisório da WFTO, haja vista que a inconformidade no preenchimento dos critérios inviabilizaria a membresia. Posteriormente, houve a verificação das informações fornecidas de acordo com a regulamentação normativa e,

\footnotetext{
${ }^{2}$ Embora não seja o objetivo desse artigo discutir a relação patronal do SEBRAE na assessoria de uma cooperativa no âmbito do Comércio Justo, não se pode deixar de perceber, certa incongruência política, ideológica e mesmo normativa.
} 
caso estivesse em desacordo, a própria WFTO apresentaria um sistema de non-compliance (não conformidade).

Assim, além das auditorias realizadas por experts da organização, do acompanhamento/participação de outros membros regionais na implementação dos critérios obrigatórios e de melhoria continua e dos questionários de auto avaliação que compõem o sistema de conformidade da organização, há ainda um campus de non-compliance no sítio eletrônico da WFTO. (WFTO, 2017) Por meio de tal ferramenta, qualquer indivíduo que conheça alguma atividade contrária aos princípios do Fair Trade sendo praticada por uma instituição aceita como membro provisório (que teve o auxílio de consultoria ou não) poderá denunciar tais práticas diretamente à WFTO, que promoverá investigações necessárias e medidas cabíveis. Como a transparência é um dos parâmetros pregados pelo Fair Trade e também pela organização em questão, a publicidade dos canais de conformidade é de amplo e fácil acesso a todos interessados em auxiliar na construção do movimento. (WFTO, 2016)

A partir da percepção do Fair Trade e das práticas de assistência no desenvolvimento da comunidade, o SEBRAE iniciou a pontuação dos critérios obrigatórios e requereu a conformidade para ingresso na rede WFTO América-Latina. Desde então, diversas melhorias foram realizadas na Associação com foco na eficiência operacional de aquisição de matéria prima - eliminando os atravessadores - e na sustentabilidade social concernente à aquisição e ao melhoramento dos equipamentos e infraestrutura. Os teares foram adaptados para proporcionar ergonomia adequada e os resíduos de estufa de fumo foram imediatamente abolidos pelas artesãs. Após um ano e meio de adaptação aos critérios de conformidade (alguns dos quais já foram citados - sendo todos encontrados no handbook disponível no sítio eletrônico da WFTO), em agosto de 2010 a instituição requereu a membresia provisória perante a organização WFTO América-latina. Três anos depois, após procedimentos de certificação de conformidade e burocracias documentais, em 2013 o projeto Toca Tapetes foi aceito membro provisório.

Para validar o formulário de conformidade de critérios preenchido encaminhado à WFTO e, para auxiliar na avaliação de membresia, três outros membros regionais deslocaramse para o município de Araranguá e auxiliaram a organização na conclusão do procedimento. 
No entanto, por opção da instituição Toca Tapetes, no ano de 2014 a implementação dos critérios para obtenção do título de membro permanente foi interrompida e a instituição deixou de fazer parte da cadeia de membros da WFTO, fator justificado especialmente pelo término do Projeto que o SEBRAE mantinha enquanto decorrência de um Edital. Com isso, os demais procedimentos percorridos até a obtenção do grau máximo de membro definitivo não ocorreram. Em que pese a descontinuidade, a experiência Toca Tapetes revelou como o movimento de Fair Trade pode modificar parâmetros laborais e modos operacionais, fazendo com que o propósito não seja exclusivamente a obtenção de lucro, mas a possibilidade de sustentabilidade social. Nesse sentido, contribuiu também a conscientização da comunidade e das famílias e envolvidas, com destaque para a obtenção do lucro obtido de forma consciente, levando-se em consideração as prerrogativas essenciais do ser humano.

\section{Conclusão}

No intuito de alcançar relações comerciais justas e solidárias, emergiram os parâmetros do Fair Trade em período ulterior ao encerramento da Segunda Guerra Mundial. Aspectos de sustentabilidade fizeram coro com a emergente proposta, de maneira que a justiça social fosse viabilizada de maneira instrumental. Do ponto de vista do consumo, percebeu-se que seria preciso mudar o foco da satisfação individual para defesa dos interesses das presentes e futuras gerações.

Para reger essa tendência, emergiram princípios jurídicos, regras de certificação e códigos de conduta institucionalizados, especialmente capitaneados pela WFTO. Tratava-se de rede global, com escritórios regionais nos cinco continentes que se apresentava como Organização a lutar contra a pobreza e as desigualdades no comércio por intermédio de um sistema de Comércio Justo. O corpo normativo da WFTO, verdadeira experiência de direito transnacional, refletia estímulos jurídicos para mudança do comportamento consumerista enquanto agente de transformação social. Para atestar essa emergente realidade um certificado de Conformidade passou a ser a marca da sustentabilidade. Em virtude da polêmica que gira em torno da autenticidade das certificações, a WFTO criou um sistema de alerta que monitora os atores envolvidos para qualquer espécie de irregularidade. Além disso, há o denominado compliance criteria, ou seja, requisitos que uma organização deve cumprir para ser aprovado como um membro da WFTO e continuar associado. 
Com a observância da experiência brasileira Toca Tapetes em alcançar a membresia provisória da WFTO América Latina, verifica-se que a certificação de Fair Trade é uma possibilidade em fornecer reconhecimento da correta implementação de princípios comerciais justos. Com efeito, após analisados os critérios de conformidade tornou-se sensato afimar que o sistema de certificação possibilita a conscientização e a adequação dos próprios produtores envolvidos no movimento, além da já mencionada garantia ao consumidor. A cada procedimento de certificação, as regras de implementação e critérios de conformidade são aprimoradas para as especificidades do comércio desenvolvido pelos membros para que permaneça justo, resultando na melhoria na qualidade de vida dos produtores, bem como na propagação do movimento.

\section{Referências}

ARECHAGA. Andrés Larrinaga. Construit algo nuevo: reubicando el comercio justo. In: MONTAGUT; VIVAS (orgs). Adónde va el comercio justo?. Barcelona: Icaria Más Madera, 2006.

BARRIENTOS, S.; CONROY, M; JONES, E. Northern social movements and Fair Trade. In: RAYNOLDS; MURRAY; WILKINSON (orgs). The challenges of transforming globalization. Nova Iorque: Routledge, 2007a.

BARRIENTOS, S.; SMITH, S. Mainstreaming Fair Trade in global production networks. In: RAYNOLDS; MURRAY; WILKINSON (orgs). The challenges of transforming globalization. Nova Iorque: Routledge, 2007b.

BARROS-PLATIAU, Ana Flávia. Novos Atores, Governança Global e o Direito Internacional Ambiental. Disponível em: <http://www.egov.ufsc.br/portal/sites /default/ files/anexos/31997-37543-1-PB.pdf> Acesso em: 23/07/2017.

BESSON. Michael. Que modelo de comercio justo?. In: MONTAGUT; VIVAS (orgs). Adónde va el comercio justo?. Barcelona: Icaria Más Madera, 2006.

CLAC. (World Fair Trade Organiza Coordinadora Latinoamericana y del Caribe de Pequeños Productores y Trabajadores de Comercio Justo). Antecedentes Disponível em: <http://www.clac-comerciojusto.org/> Acesso em: 05/08/2017.

FAJARDO, Elias. Consumo consciente, Fair Trade. Rio de Janeiro: Senac Nacional, 2010.

FLORES. Alberto Gómez. Él comercio justo y las organizaciones campesinas mexicanas. In: MONTAGUT; VIVAS (orgs). Adónde va el comercio justo?. Barcelona: Icaria Más Madera, 2006.

Revista de Direito, Globalização e Responsabilidade nas Relações de Consumo | e-ISSN: 2526-0030 | Maranhão | v. 3 | n. 2 | p. 22 - 42 | Jul/Dez. 2017. 
GOMES, Rosemary. A Economia Solidária na América Latina e no Caribe. Disponível em: < http://facesdobrasil.org.br/ponto-de-vista/a-economia-solidaria-na-america-latina-e-nocaribe> Acesso em: 11/07/2017.

GRODNIK, A.; CONROY, M. E. Fair Trade coffee in the United States. In: RAYNALDS; MURRAY; WILKINSON (orgs). The challenges of transforming globalization. Nova Iorque: Routledge, 2007.

IBASE (Instituto Brasileiro de Análises Sociais e Econômicas. Comercialização e Certificação Participativa. Disponível em:

$<$ http://www.fbes.org.br/index2.php?option=com_docman\&task=doc_view\&gid=1362\&Itemi $\mathrm{d}=8>$ Acesso em: 16/07/2017.

KRUGER, S.; TOIT, A. D. Reconstructing fairness. In: RAYNALDS; MURRAY; WILKINSON (orgs). The challenges of transforming globalization. Nova Iorque: Routledge, 2007.

MORETTO, Luis Moretto; SCHMITT, Valentina Gomes Haensel. Associativismo, Comercio Justo e o Desenvolvimento Territorial Sustentável: A Experiência Toca Tapetes. Disponível em: <http://www.revistas.usp.br/rege/article/view/36741>. Acesso em: 10/07/2017.

MURRAY, D. L.; RAYNOLDS, L. T. Globalization and its antinomies. In: RAYNALDS; MURRAY; WILKINSON (orgs). The challenges of transforming globalization. Nova Iorque: Routledge, 2007.

SEBRAE. O que é Fair Trade (Fair Trade). Disponível em: <https://www.sebrae.com.br>. Acesso em 05/08/2017.

STELZER, Joana; GONCALVES, Everton das Neves. Da tripla dimensão do comércio mundial: multilateralismo, regionalismo e Fair Trade. In: SILVEIRA, Vladmir Oliveira; SILVA, Karine de Souza; ANGELIN, Rosangela. (Org.). Direito Internacional. Florianópolis - SC: CONPEDI, 2014, v. 1, p. 258-285.

STELZER, Joana; GONCALVES, Everton das Neves. Greenwashing e a Certificação no Fair Trade e Solidário: Consumismo e Sustentabilidade na Formação da Sociedade Transnacional. In: STELZER, Joana; CARMO, Valter Moura do. (Orgs.). Direito, Globalização e Responsabilidade nas Relações de Consumo. Florianópolis - SC: CONPEDI, 2016, v. 1, p. 172-191.

WFTO. (World Fair Trade Organization). Home; History of WFTO; Who are we;Our guaratee system. Disponível em: <http://www.wfto.com/> Acesso em: 30/06/2017a.

WFTO. (World Fair Trade Organization). Guarantee system handbook. Disponível em: < http://wfto.com/sites/default/files/Ch-6-WFTO-Fair-Trade-Standard-draft-3.6-feb-14.pdf> Acesso em: 13/07/2017b. 